\title{
Gender quotas or girls' networks? Evidence from an Italian research selection
}

Daniele Checchi (University of Milan, Irvapp and IZA)

Nevena Kulic (EUI)

Simona Cicognani (Free University of Bozen)

This article investigates the role of the gender composition of selection committees and the role of connections in promoting women in research activities. Exploiting a newly collected data set on recruitment processes to entry-level research positions in a leading Italian research centre operating mainly in the hard sciences, the study finds that bias against women manifests itself at non-tenured entry level and is attenuated by the presence of a woman on the selection committee. However, the most important predictor for recruitment in the study is previous connections with the research centre, a mechanism which, due the lower density of network links with the institute among female candidates, operates as a selection device discriminating against women. The results suggest that gender of the committee members, network structure and type of recruitment must all be taken into account in approaching recruitment policy and that very early stages of scientific careers are crucial for addressing gender bias in research.

Keywords: Connections, Gender bias, Gender quotas, Italy, Research recruitment 


\section{Introduction}

In a recent press release, the League of European Research Universities stated that as of 2015 "not enough women enter or remain in the research profession and very few are in leadership positions" and that universities failed to make structural changes to facilitate the inclusion of female academics (LERU, 2015).The European Commission reported that in 2012 women outnumbered men by $9 \%$ among students completing university studies, but they were under-represented compared to their male colleagues in top academic positions (EC 2016). This phenomenon is commonly known as the 'leaky pipeline' or 'glass ceiling' effect, with both metaphors evoking the difficulty in gaining equal access to the top for women, and applies not only to academia but also to other fields and professions (Blickenstaff, 2005; Beirne and Wilson, 2015).

This article contributes to the literature on the determinants of entry and career progression for female academics and researchers, with a focus on the Italian research community. Italy constitutes an interesting setting to investigate for more than one reason. On the one hand, in terms of the gender composition of academics, Italy ranks low among OECD countries in terms of women presence in top rank positions. Using the Italian ministry data, Frattini and Rossi (2012) report that there has been some progress in the participation of women in academic positions over time, especially at the lower levels of the career ladder, but leaving the percentage of women in Full and Associate professorships quite unchanged (respectively $23 \%$ an $37 \%$ in 2017 - see also ANVUR 208). In other words, it is still significantly harder for women to access, progress and pursue a career in Italian academia. On the other hand, the job market for research positions is more segmented than in other countries: while universities are perceived as the most appealing workplaces, public research institutions come second, whereas private research centres exist in a 
limited number. The hiring freeze that hit Italian universities over the period 2008-2012, for budget reasons, prompted many young scholars to search for opportunities either in foreign universities or in research institutes.

The specific focus of this article is the recruitment practices in an Italian hard science research institute, which is one of the largest public research centres in the north-eastern part of Italy. The study investigates whether there is bias against women in the selection process for entry-level positions and whether a higher proportion of women on selection committees could raise the proportion of women selected for research jobs. In studying these issues, this article focuses on the role of connections in the application process from a gender perspective. Several questions can be raised in this respect: Are connections important? Are they gender-neutral? Can a potential initial disadvantage for women be compensated by strong ties with committees or with the institution under study? Does being connected help women and men differently?

Gender discrimination in academic or research competitions might be one of the reasons for the current underrepresentation of women, possibly because very few women are eligible to participate in committees evaluating new entrants (De Paola and Scoppa, 2015). One direct affirmative action in this context consists of imposing gender quotas on selection boards. This has already been introduced in some European countries, and the European Commission has recently advocated the policy as a desirable tool to countervail gender inequality in the academic sector (Meulders and O’Dorchai, 2013, p. 7). Yet, imposing gender quotas on scientific selection committees does not represent a zero-cost policy since it requires a disproportionate share of senior women's time to be spent attending selection committees and thus decreases the productive activity of female researchers. 
The contribution of the article is threefold. First, in contrast to previous studies, it investigates gender bias in non-academic research positions. The non-academic research environment is important in its role of second-best alternative, as women are disproportionately scarce in tenuretrack positions, and tend to leave academia towards adjunct positions and research fellowships outside of universities (Wolfinger et al., 2009). Second, this study examines recruitment processes, not career advancement. The recruitment strategy studied here operates mainly at the lowest research levels, equivalent to post-doctoral or research fellowship positions at universities, and no other study about Italy has so far investigated gender bias at the start of the research career. This is an important layer of the research ladder, because it may be the starting point of divergence in female and male research careers. Third, the article studies research connections as a potential explanation for gender imbalance in research, given its discretionary nature that allows for discriminating against or favouring female researchers.

Although we believe that the research centre under study is not dissimilar from other Italian research centres in STEM sectors in terms of selections for entry positions and has common grounds with close-by Italian Universities, we limit our conclusions to this centre and do not generalize the results to Italian academia as a whole. We trade the possibility for generalization that could be obtained through data sets encompassing the whole academia with an insight into innovative data set containing unique administrative information on selection procedures taking place in a subpopulation-specific research institute (Duncan, 2008). The advantage of this study is therefore that detailed administrative data on hiring enable us to test in a more precise way the theoretical mechanisms of bias against women in research recruitment and discuss its theoretical implications for similar research organizations. 


\section{Previous research}

Underrepresentation of women in the research profession has triggered interest among scientists to understand the underlying reasons. The existing literature contains two streams of research: explanations based on differences in characteristics and/or behaviours between female applicants and non-applicants, and explanations centred on the discriminatory behaviour of employers. On the one hand, several important factors are found to play a role when a woman decides to apply for research positions: performance and achievements in previous stages of the career (Wolfinger et al., 2009); the burden of childrearing and a quest for balance between work and family (Shen, 2013); the level of risk aversion, confidence and competitiveness (Azmat and Petrongolo, 2014). On the other hand, bias against female candidates in the selection procedure is one of the reasons why women are prevented from entering and reaching the upper levels of an academic career. As explained by Ridgeway (2009), gender is one of the primary cultural distinctions that brings with it expectations about sexuality and reproduction, influencing social interactions and expectations. The origins of the bias may be different. First, there is "taste bias" when women are excluded based on prejudice and sexist views (Ellioth and Smith, 2004) or ideological beliefs about who is eligible for certain professions (Witz, 1990). For example, academic research is often considered an environment particularly suitable for (white) men (Dressel et al.,1994). Second, there is status-based discrimination where gender is viewed as a status characteristic and women as a group are perceived as less productive and less committed (Ridgeway and Kricheli-Katz, 2013). However, productivity concerns may also be related to woman's partnership status, as female academics with partners may be considered by selection committees as more likely to make career concessions (Rivera 2017). Also, expectations for low productivity may originate from the possibility that women are (or are likely to become) mothers, because a mother's status is seen as a deviation from 
the notion of an ideal worker, and the effort of mothers as a group is considered low (Correl et al., 2007). This is due to a frequent pattern of work interruptions and part-time employment that characterizes mothers but not fathers, especially during the early age of their children. It is difficult to distinguish between these different types of bias against women in empirical research, and most often the distinction is neglected. In addition, bias in evaluations can come from both genders. In a recent article, Moss-Racusin et al. (2012) find an intrinsic gender bias against female researchers in STEM disciplines that influences the choices of professors of both genders. However, more often the empirical literature finds that the chances of success of female candidates are limited by a potential gender bias of male professors or male committee members. Wold and Wennerås (1997) report evidence of bias against female candidates in applications for fellowships in the Swedish Medical Research Council. Similar evidence is reported by De Paola and Scoppa (2015) and Bagues et al. (2017) for the qualifications for associate and full professorships in the Italian academic community; similar results are also observed for internal promotions within Italian faculties (Marini and Meschitti, 2018).

Gender diversity in selection committees has lately been recommended as a way of contending biased decisions of male selectors with respect to the gender of the candidates. The mechanism of group interaction in mixed-gender groups can be different in comparison to same-gender groups (Bratton, 2005; Ridgeway and Correll, 2004). Men and women may be different in their preferences and choices, and also in the way in which they behave (Apesteguia et al., 2012), influencing the group interaction and the outcome of decisions. In the particular case of selection committees, women may influence the final decision on the candidates through their own vote as well as by influencing the votes of the other committee members. However, the effect of the gender composition of selection committees on decision making is hard to predict. On the one hand, a 
greater female presence on committees could broaden preferences, representing more diverse models of scientific careers, and prevent bias against women: as a consequence, this would drive decisions to hire more women as scientists (Azmat, 2014). On the other hand, the relationship between female presence and selection of women could be non-linear, thus raising the issue of a minimum threshold of female presence required in order to affect decisions in favour of women. Kanter (1977) stipulates that a different proportion of women in a group may lead to different outcomes of decision making. Based on the percentage of women in groups, she identifies homogenous groups with complete dominance of either men or women in the group, skewed groups with a large $(85 \%)$ dominance of one gender, tilted groups with the ratio of $65 \%$ to $35 \%$ and balanced groups in the intermediate shares. In this classification, there are token women when they represent an important minority below $15 \%$. Applied to selection committees, this means that the influence of women can be somewhat symbolic or substantial, depending on their actual share. This classification led to the expectation of many authors (see for instance Sarah and Mona, 2008) that only a critical mass threshold, which corresponds to at least $35 \%$ of women, could serve the interests of applicant women. Following the above arguments on the presence of gender bias in evaluation and the positive role of mixed-gender committees for the selection of women, one may expect that committees composed of men are potentially biased against women and that a female presence on the committee increases the likelihood of a woman being selected, the more so if the presence of women is above the critical threshold of $35 \%$.

Another important mechanism in which gender inequality and bias in scientific research can take place is through informal and formal professional connections. These connections facilitate entry in academic jobs (Forret and Dougherty, 2004), and help improving career prospects and job opportunities. Co-optation through informal networking has traditionally been one of the principal 
means of recruitment in academia (Van Den Brink and Benschop, 2012b; Wold and Wennerås, 1997). In a similar vein, candidates' connections with the academic élite and eminent professional networks may help the dissemination and citation of scientific publications (Van den Brink and Benschop, 2012a), but may also be directly responsible for the recruitment of new researchers and scientists (Zinovyeva and Bagues, 2015). However, women tend to be less involved in high-status professional networks and powerful coalitions (Van Den Brink and Benschop, 2012a), especially in male-dominated fields, and are less likely to profit from informal connections (Forret and Dougherty, 2004). One potential explanation is homosocial reproduction (networks between similar individuals), which particularly affects men's career development. Although research shows that both men and women are equally likely to engage in the processes of homo-social reproduction, men are in better position to apply this strategy as they outnumber women in relevant positions and are more often able to provide network assistance to similar colleagues (Ellioth and Smith, 2004). Applied to the research environment, one of the reasons for the under-representation of women in networks and research might be that women find themselves more often evaluated by male (dissimilar) colleagues and superiors who often apply standards of entry more suitable to their dominant group (Van Den Brink and Benschop, 2012a). Based on the above-mentioned literature, one may expect a strong role of academic connections in recruiting researchers and hypothesize that connections are gendered in favour of men, thus influencing the final selection of the candidates. 


\section{Institutional background}

\subsection{The research institute}

This article utilises empirical data collected at a research institute level, covering the years 20092011. The institute is a public, non-profit research organization based in the north of Italy, whose core activity is research in hard science, although some research also concerns social sciences and humanities. It currently hosts about 350 researchers, employed in several research units. The institute has an excellent reputation and attracts many young researchers, not only from the local universities but also from other Italian regions and from abroad. It offers a highly competitive salary system compared to other European countries, and certainly above Italian standards for equivalent positions in academia. In this sense, the institute parallels the Italian academic system, providing a valid occupational alternative to professorships in universities, sustained by salaries and funding competitive to European levels. However, given the public nature of the organization, recruitment procedures must comply with minimum standards of transparency and publicity, which are rather similar to rules prevailing in Italian academia (and more generally to the entire public administration). The institute offers both tenure-track and non-tenure-track positions, where the first group enables researchers to progress within the institution, and the latter is characterized by temporary employment conditions without direct eligibility for higher-level positions (post-doctoral fellows, short-term grants and research analysts).

\subsection{The selection process}

The selection procedure for hiring new researchers relies on a publicly advertised call and follows the rules and stages outlined in the internal guidelines of the institute. The selection of researchers 
for both tenure-track and non-tenure-track posts consists of four stages. In the first stage, a selection committee carries out a first screening of applicants based on CVs and (if applicable) reference letters, yielding a shortlist of at most 20 candidates. In a second stage, short-listed candidates are then interviewed by the same committee. This second phase assesses the suitability of the candidates, and produces a second shortlist of qualified candidates, ranked according to their quality and adequacy for the position. Finally, the post(s) is offered to the highest ranked candidate(s); if the offer is rejected, the second-best ranked candidate receives the offer, and the process continues until either the offer is accepted or the list of qualified candidates is exhausted.

Each selection committee consists of up to five members and is typically composed by senior researchers working in the same research unit(s) that opened the hiring procedure; they are often complemented by on officer from Human Resources Department, in order to check the consistency of the procedures. The committee members are appointed by the head of the unit or the centre on the basis of their being experts in the research domain of the call. They are not made public in advance, and are therefore unknown to the potential candidates in the moment of application.

\subsection{Data}

The data used in this study were purposely collected from three main sources: applicants' CVs, the administrative archives of the institute and the Scopus bibliometric database, which was used to retrieve information on candidates' and selectors' research output. ${ }^{i}$ These three sources lead to a multilevel design of the analysis, since the data relate to both the individual applicant and the call level. 
The final sample excludes both the competitions with only one applicant and competitions without selected winners. It also excludes competitions with focus on humanities, given the small size of these research units and the absence of largely accepted bibliometric criteria. As a result, the final dataset contains 608 applicants for 78 calls. Table 1 reports the split per year of application. The calls examined here were all public, open to both external and internal candidates. More information on the data set is available in the Online Appendix.

[TABLE 1 here]

\subsection{Variables}

\subsubsection{Candidate-level variables}

The dependent variable in the analysis is the dummy variable Success $i j$, which takes value 1 if the candidate $i$ was eventually selected in call $j$ and 0 otherwise. The main covariates consist of a dummy for the gender of the candidate (value 1 if the candidate is a woman), and an interaction term between the gender of the candidate and a dummy for the presence of a female researcher on the committee. Other covariates included in the analysis relate to the candidate socio-demographic characteristics, education and field of study, work experience, scientific productivity (publications and H-index, retrieved from Scopus) and pre-existing ties with the research institute. These, as well as a detailed description of the variables categories, are reported in the Online Appendix.

The H-index is standardized by applicants' field of research. The research field is recoded in three main areas, according to the very heterogeneous publication propensities across the disciplines: 1) social sciences correlated to engineering research areas (like management, human resources); 2) hard sciences (physics, chemistry, geography), excluding mathematics; 3) engineering, computer 
sciences, architecture, environmental sciences and mathematics. Unfortunately, no information can be gathered on the marital status or the number of children of the candidates (relevant especially for female candidates). However, given the relevance of child rearing activities for a correct measure of woman's scientific productivity, we adjust the H-index for the fertility patterns of women currently employed at the institute, under the assumption of similarity of the two populations (those already hired and the applicants). With this procedure we impute a maternity risk to each female candidate, according to her age, based on the age distribution of first maternity in the population of women currently employed at the institute. The age profile of these risks is computed under a lowess estimator. ${ }^{\text {ii }}$

Finally, candidates' pre-existing ties with the institute are captured by a dummy variable, Ties with the institute, which takes value 1 if the candidate had prior ties with the institute or with one member of the selection committee, either in the past or at the time of the application. Candidates are classified as having a pre-existing tie with the institute if they meet at least one of the following criteria: 1) co-authorship with a member of the selection committee; 2) being supervised at the master or Ph.D. level by one of the committee members; 3) prior work experience (including internship) at the institute; 4) current work experience (including internship) at the institute; 5) an indirect tie with a committee member due to belonging to the same internal network (Colussi, 2015) (e.g. the selector co-authors with the Ph.D. supervisor of the candidate, or the selector co-authors with the co-authors of the Ph.D. supervisor, or the selector co-authors with the co-authors of the candidate). Although reference letters often follow the application procedure, they are not collected in the data set, and therefore not used to generate the variable indicating ties. Cases 1), 2) and 5) are referred to as "committee ties" and 3) and 4) as "institution ties", with the underlying hypothesis that ties with the institution may exert a stronger effect on the hiring procedures, since a candidate 
with prior or current work experience at the institute may have had more opportunities to show her skills and/or to create networks within the hiring institution. Moreover, it is possible to identify gendered ties on the basis of the genders of candidates and their respective direct connection in the committee or within the institute. Even if four different combinations are theoretically possible male candidate/male contact, female candidate/male contact, and so on - only the first two are encountered in the data set. This is due to the vast majority of male directors and superiors within the research institute considered. The cases when it was impossible to identify the gender of the contact in the committee or within the institute are referred to as "undefined". A variable Intensity of ties, counting the presence of multiple ties, is also introduced: it ranges from 0 to 5, which is the maximum number of different connections outlined above (e.g. a value of 2 means an accumulation of two types of connections for the same candidate).

\subsubsection{Call-level variables}

For each call, the characteristics of the members of the selection committee are included in the data set, jointly with information about the vacancy advertised. For committee members, gender, age and country of origin were obtained from the administrative archives of the institute, and their bibliometric indices retrieved from Scopus for the year of the call. The latter data provide a measure of the scientific impact of the committee members, which could be positively correlated with the use of bibliometric measures in the selection (De Paola et al., 2015). A distinction between researchers and HR staff is preserved. The gender presence on the committees is described by a dummy variable, Female (no HR) in committe $_{j}$, taking value 1 if the committee includes at least one female research member among the total number of committee members (beyond the potential presence of female administrative staff on the committee). At the call level, information on the 
duration of the contract (in months), the salary and the type of position advertised is collected. The positions advertised are classified into the following categories: 1) tenure-track positions (internally coded as R3-(senior)-level researchers and R4-(junior)-level researchers), 2) non-tenure-track positions (internally coded as T4-level technicians - equivalent to research assistant -, post-doctoral positions and fixed-term grants - called “co.co.pro.” according to Italian labour law).

\subsection{Descriptive statistics}

Table 2 and Table 3 give an overview of the candidates' and the committee members' main characteristics.

[TABLE 2 here]

[TABLE 3 here]

There are marked differences between the male and female candidates in their characteristics and research productivity. In addition, the average male candidate differs from the female one in a higher intensity of ties (1.42 vs. 1.13), and in the maximum number of ties (four types of connections vs. a maximum of two for females). $69.2 \%$ of connections are male-male direct connections, $20 \%$ are female-male connections and $10.8 \%$ are undefined. Finally, women are underrepresented in the ties with committees.

The committees include at least one female researcher only in $17 \%$ of the cases. In addition, the percentage of female researchers on the committees varies little, as on average only one member of scientific personnel is a woman. There is one outlier competition with four female researchers on the committee. If one excludes this competition and once a female researcher is on the committee, 
the average share of female researchers is $31 \%$ of the total of commissioners. Additional tables are available in the Online Appendix.

\section{Empirical analyses}

\subsection{Gender composition of committees and female success}

\subsubsection{Analysis on the full sample}

To examine the effects of the gender composition of the committee on the probability of being hired, we estimate the model:

Success $_{i j}=\beta_{0}+\beta_{1}$ Female $_{i j}+\beta_{2}$ Female $_{i j} \times$ Female $_{(\text {no HR }) \text { on }_{\text {committee }}}+\beta_{3} X_{i j}+\varepsilon_{i j}$

where Success $_{i j}$ is a dummy variable taking value 1 if candidate $i$ was selected for call $j$ and value 0 otherwise. Controls for gender of the candidate, Female $_{i j}$, and interaction between her gender and a dummy variable indicating the existence of at least one woman on the committee, Female $_{i j} \times$ Female (no HR) on committee are included. Thus, $\beta_{1}$ indicates the effect of being female on the probability of being selected by an all-male selection committee, whereas $\beta_{1}+\beta_{2}$ indicates the effect of being female on the probability of being selected by a mixed-gender committee. All committees are considered net of presence of Human Resources, and refer to research staff. $X_{i j}$ is a vector of candidate attributes, such as age and origin, a dummy for holding a Ph.D., years of work experience, the standardized $\mathrm{H}$-index at the year of the competition (with the standardization 
implemented among applicants and within field of research, as outlined in Section 3.4.1) ${ }^{\mathrm{iii}}$, and the presence of pre-existing ties with the institute.

Equation (1) is estimated using a conditional logit model, hence through conditional maximum likelihood estimation. The conditional logit allows taking into account the candidates' interdependent probabilities of being recruited: the likelihood of an outcome is conditional on the number of positive outcomes (in the present case, success) within the group. For almost all the calls in the dataset only one candidate was selected per call and hence the group at the basis of the conditional logit is composed by candidates applying for the same call. Hence, the differences across candidates are considered at the call level. This characteristic of the conditional logit estimation allows to implicitly take into account fixed effects of the call (conditional logit is also referred to as "conditional fixed-effects logistic regression"). Estimated coefficients for the conditional logit are displayed in Table 4.

The Equation (1) is also estimated using a Linear Probability Model (LPM), whose coefficients are closely related to average marginal effects (Mood, 2010). Estimates from both conditional logit and LPM are utilized to avoid a potential presence of unobserved heterogeneity influencing comparisons of coefficients within and across conditional logit models, leading to biased results. In case of LPM, Equation (1) also incorporates a call fixed-effects term, $\mu_{j}$, which includes both the type of position and the area of specialization, as well as other call level factors that may influence the candidates' probability of success. The LPM also allows direct interpretation of non-linear interaction effects in the form of marginal probabilities (Buis, 2010). The coefficients of LPM are provided in the Online Appendix and are discussed in the text. They mostly confirm in sign and significance the estimates obtained by conditional logit. 
[TABLE 4 here]

In Table 4, column 1, one may observe whether there is an overall lower probability of female candidates being recruited. The results reject this hypothesis. However, when examining the effect of the gender composition of the committee in column 2, it becomes apparent that committees with a female committee member tend to increase the chances of female candidates. As reported in Table A6 of the Online Appendix, the chances of female candidates are 20.5\% higher in such case. This also holds true if one includes a measure of the candidates' scientific productivity, the standardized H-index, as in Table 4, column 3, although the chances become slightly lower.

After including the individual characteristics (Table 4, column 4), the interaction between the gender of the candidate and the presence of women on the committees retains sign as in the previous models but remains significant only at 10\%: as shown in Table A6, the probability that a female researcher will be hired increases by $17.5 \%$ if there is a female researcher on the committee. Finally, in the full model in Table 4, column 5, the pre-existing ties variable exhibits a positive and highly significant coefficient, while the interaction term is no longer significant. In other words, the number of women on the committee does not seem to make a difference to the selection of female candidates when taking into account the connections with the research institute.

Analyses were run on both all competitions and on all competitions except the outlier competition characterized by four female researchers on the selection committee. In the latter version, even though the sign of the interaction term is confirmed, its significance disappears already in Model 3, implying that results are less robust when the average number of women on the committee is below the critical mass threshold. It is worth noting that the measure of scientific productivity loses its significance when work experience and geographical origin of the candidates are introduced in 
columns 4 and 5. In addition, the measures of geographical origin show that non-EU candidates have lower chances of being selected in comparison to all other groups ${ }^{\text {iv }}$.

\subsubsection{Analysis on sub-samples of candidates}

In this section, previous analyses are replicated on sub-samples obtained by splitting the original data set according to relevant call-level variables (Table 5). First, the sample is divided according to the average H-index of all the selection committees (top quartile vs lower quartiles). This is intended to investigate whether selection committees characterised by different scientific visibility (bibliographic production) adopt different criteria in the hiring process. Second, models for nontenure-track and tenure-track research positions are separately considered. These positions differ in the opportunities for career and internal promotion, thus they could also exhibit different hiring patterns. Moreover, in Table 7, low paid and highly paid positions are separately considered. These differ in: i) their level of attractiveness to the candidates, and ii) costs to the employing institution. The latter might induce differences in the way the candidates are treated in the selection procedure.

The results of the models based on the sample split according to scientific productivity of the committees $^{\mathrm{v}}$ show that the presence of female committee members does not seem to matter in promoting female candidates in the committees with lower scientific productivity, after controlling for individual characteristics and the presence of ties. In addition, the committees with lower bibliographic production seem to be highly susceptible to the influence of networking patterns and internal connections. On the contrary, committee members in the top quartile of scientific productivity seems to be insensitive to prior connections with the institute, a result that indicates greater attention to measurable qualities in contrast with the general model shown in Table 4. 
When it comes to non-tenure-track and tenure-track positions, results suggest that females applying for non-tenure-track jobs have, ceteris paribus, a lower probability of being hired by all-male committees, and this effect is significant both with and without the control for ties. In other words, the chances of female researchers to be hired are lower by $10.2 \%$ and $9.3 \%$ respectively when evaluated by all-male committees (Table A7 of the Online Appendix, columns $3 \mathrm{a}$ and $3 \mathrm{~b}$ ). This result shows bias against women in hiring. However, a female member on the committee increases the chances of hiring a female researcher in non-tenure jobs by $22.9 \%$, thus attenuating the bias (Table A7, column 3a).

When moving from the specification without ties with the institute to the specification with ties, the positive coefficient for the interaction between female candidates and the dummy for female committee members reduces its significance to $10 \%$, while LPM in Table A7, column 3b, reports the average marginal probability of $18.9 \%$. This suggests that also in this case female committee members might have previous connections with the female candidates.

When looking at recruitment for tenure-track research positions, being a woman becomes a secondorder effect. There is no evidence of observables affecting the probability of recruitment except geographical origin and having prior ties. This means that recruiting at higher levels follows different logics: being local and well networked with the institute seem to matter the most.

\section{[TABLE 5 here]}

When splitting the data set according to the median wage in the sample (around 2800 Euros per month, gross), we do find evidence of discrimination against female candidates for lower paid positions, and also a positive and significant coefficient of connections for these positions. This allows us to disentangle the role played by tenure and by wage: indeed, connections always 
mattered irrespective of tenure, whereas higher paid positions seem to be unrelated to connection mechanisms (this result is confirmed in the LPM of Table A8).

\section{[TABLE 6 here]}

\subsection{Gender, ties and recruitment}

The previous analyses have shown that selection committees are mostly male-dominated and that there is little variability in the female participation to the committees. In most competitions, the presence of women consists of just one woman, although their share varies according to the total number of the committee members. The present data set includes only one competition (amounting to 11 observations) with four women on the committee, thus representing an all-female committee. Interestingly enough, in all cases where a male candidate is successful, no female researcher is present on the evaluating committee, whereas in $36 \%$ of the cases when a female candidate is selected there is at least one female researcher on the committee. ${ }^{\mathrm{vi}}$ One can also observe that in almost any model specification and sample split, the most important factor affecting the probability of recruitment is pre-existing ties with the institute. Table A10 in the Online Appendix reports the predicted probabilities of success for female and male candidates with different profiles (gender, ties, and female presence on the committee) net of other characteristics, computed from estimated coefficients of the main model in Table 4 and the same model with three-way interactions. The difference in probabilities of success between having ties and not having ties for male candidates amounts to $35 \%$ in comparison to $23 \%$ for women, showing how the ties for male candidates might be more effective. This could represent an alternative channel through which a gendered selection may take place, since prior ties precede the actual selection process. Table A9 further shows that when a woman is not on the committee, hiring probabilities of female candidates increase only by 
$10 \%$ in the presence of ties. On the contrary, once a female member is on the committee, the presence of ties adds $35 \%$ of probability of winning. To sum up, it seems that indirect links (with female members of the committee) seem to explain in part the higher propensity for a female to win a competition if at least one of the committee members is a woman, as well as male-male connections might be responsible for recruiting male candidates.

To shed more light on the process, the impact of different types of ties with the institute on the probability of being recruited is examined in two ways in Table 7: first, the conditional logit model in Table 4, column 5, is replicated replacing the variable Ties with the institute with the two variables representing ties with the institution and ties with the committee. Second, the same model is estimated replacing the two dummy variables with the Intensity of ties indicator. Third, Ties with the institute is replaced with gendered connections: male-male, female-male connections, and a category with observations where gendered links could not be attributed. The gender of the candidate is linked to the gender of the official tie, which does not exclude the existence of informal ties with female committee members. The data set, however, includes only two types of gendered connections based on a formal contact: male-male direct connections and female-male connections (see Table A5 in the Online Appendix).

\section{[TABLE 7 here]}

The results in Table 7 show that the most effective ties in terms of probability of success in the competition are ties with the institution, in line with our predictions. Hence, it seems that having worked or currently working at the research centre is the most effective channel to future employment at the centre. Female connections created while working for the institute could be a 
mechanism that explains the relationship between female committee members and the success of female candidates despite the absence of formal female-female connections.

When investigating the role of multiple ties in recruitment, by treating the different types of ties with equal weights, the results show that having an additional tie, either with the institution or with the committee, statistically increases a candidate's probability of success. Men are more likely to have multiple connections within the institution, and thus have more chances of success thanks to networking.

Finally, the model with gendered connections shows that male-male connections seem to be more effective than female-male connections, pointing to a stronger role of exclusively 'male' ties in winning the competition. The results are confirmed in LPM in Table A11 of the Online Appendix.

\section{Discussion and conclusion}

Gender disparities in many professional fields are a highly-debated topic (Beirne and Wilson, 2015). This article aims to shed light on the presence and mechanisms of bias against women in hiring procedures of an Italian research centre. Although the results are contingent to a specific research centre, implications for testing theoretical mechanisms of gender discrimination in research environments are important.

First conclusion of this article is that bias against female researchers is particularly strong at the very early stage of scientific careers potentially leading towards under-representation of women in research centres in later stages of scientific career. Our results show that all-male committees in non-tenure-track selections favour men over women after controlling for education, experience, productivity and prior connections. It is thus particularly important to address this issue and recruit 
more women at entry positions. This result is in line with the initially outlined theoretical expectations stemming from the literature on female representation in research profession (Dressel et al., 1994) and confirms the findings of some recent studies on gender bias in promotion in Italian universities (Marini and Meschitti, 2018). Although the literature reports different possible reasons for bias against women in research profession, data limitations in our study do not allow for direct testing between different forms of bias. Yet, reasons for this bias could be productivity concerns related to the short-term character of non-tenure-track positions where men are expected to perform better under pressure, or be more available to meet the demands of the employer.

The analyses show, however, that the female presence on committees attenuates this bias and helps increase the number of women hired. Interestingly, the presence of female committee members is found to facilitate the entry of female researchers also in cases when all-male committees do not necessarily discriminate against women. This might suggest that also positive discrimination for women takes place if committees are composed of both genders. In addition, the role played by female members of committees was found to be stronger once all female committee was included in our analyses, that is, once the mean percentage of women on committee in the sample was closer to the critical mass threshold (Sarah and Mona, 2008). Thus, the present article suggests that gender diversity in scientific committees may be a solution for gender-biased preferences towards same-sex candidates in selection committees, which are generally male-dominated, although the effectiveness of these teams for hiring female researchers needs to be judged relative to the varying proportion of women on committees. Finally, the decision on whether to introduce gender quotas on selection committees in specific cases and the policy-relevance of these findings would need to be evaluated against the adverse effects of these measures, such as disproportionate commitment of women serving on committees, which could influence their productivity and achievement. 
The second conclusion of this article concerns the role of ties in hiring and their gender character. Connections between candidates and the Institute, whether these are with members of the selection committee or due to prior employment are the strongest predictor of success in selection within the institute studied, after considering all observable characteristics. This is in line with the literature showing that internal networks are one of the main mechanisms of entrance in research jobs (Forret and Dougherty, 2004). It is possible that similar mechanisms can be found in other research institutions of the same nature. By breaking down the connections into different types (direct with committee members, other ties with institutes, indirect ties (wider professional networks, e.g. coauthor of a coauthor....), it is possible to identify how success varies with qualitative differences in networks: higher intensity of ties (defined as having multiple connections) and internal connections are highly related to more success in being hired. Understanding the nature of connections is also useful for understanding gender imbalance in research: qualitative differences in the number and types of connections between genders might serve as one of the explanations of different rates of success. Interestingly, connections in the present case study show clear patterns of homosocial reproduction: a vast majority of connections are male-male connections, which in our data are also the most effective in the hiring success.

Female candidates work mainly under male supervision as the heads of units/projects are in most cases men. This, however, does not necessarily mean that female networking within the institute does not take place: the analyses suggest that part of the influence of female committee members on the success of female candidates is exercised through an indirect link with the candidates, given that direct connection is not observable with our data set. One may speculate that female applicants (especially those already working in the institute) have looser informal contacts with female researchers in the institute beyond those with their direct superiors in such a way creating broader 
networks that may be helpful in the selection process. This study thus suggests that enhancing networking connections may be an important mechanism bringing equality between men and women in research. Promotion of mixed-gender mentoring, encouraging mixed-gender teams, facilitating the entrance of women in professional organizations and raising awareness of the patterns of homosocial reproduction in academic research might be some possible solutions for less gendered outcomes in hiring and should be considered along with the introduction of quotas at the committee level.

\section{References}

ANVUR (2018). Rapporto biennale sullo stato del sistema universitario e della ricerca. Rome

Apesteguia J, Azmat G, and Iriberri N (2012) The impact of gender composition on team performance and decision making: Evidence from the field. Management Science, 58(1), 78-93.

Azmat G (2014) Gender diversity in teams. IZA World of Labor 2014: 29.

Azmat G., Petrongolo B (2014) Gender and the labor market: What have we learned from field and lab experiments? Labour Economics, 30, 32-40.

Bagues M, Sylos-Labini M, and Zinovyeva, N (2017) Does the gender composition of scientific committees matter? American Economic Review, 107(4), 1207-38.

Beirne M, Wilson F (2015) Running with 'wolves' or waiting for a happy release? Evaluating routes to gender equality. Work, Employment and Society, 30(2), 220-236. 
Blickenstaff JC (2005) Women and science careers: leaky pipeline or gender filter? Gender and Education, 17(4):369-386.

Bratton KA (2005) Critical mass theory revisited: The behavior and success of token women in state legislatures. Politics \& Gender, 1(01), 97-125.

Buis ML (2010) Stata tip 87: Interpretation of interactions in non-linear models. The Stata Journal, 10(2), 305-308.

Colussi T (2015) Social ties in Academia: A friend is a treasure. Review of Economics and Statistics, (0).

Correll SJ, Benard S, and Paik I (2007) Getting a job: Is there a motherhood penalty?American Journal of Sociology, 112(5), 1297-1338.

De Paola M, Scoppa V (2015) Gender Discrimination and Evaluators' Gender: Evidence from Italian Academia. Economica, 82(325), 162-188.

Dressel P, Hartfield B W, and Gooley RL (1994) The dynamics of homosocial reproduction in academic institutions. The American University Journal of Gender, Social Policy \& the Law 2, no. 1: $37-62$

Duncan, G. J. (2008) When to promote, and when to avoid, a population perspective. Demography, $45,763-784$.

Elliott JR, Smith RA (2004) Race, gender, and workplace power. American Sociological Review, 69(3), 365-386. 
European Commission (2016). The 2015 SHE figures. Brussels (https://ec.europa.eu/research/swafs/pdf/pub_gender_equality/she_figures_2015-final.pdf)

Forret ML, Dougherty TW (2004) Networking behaviors and career outcomes: differences for men and women? Journal of Organizational Behavior, 25(3), 419-437.

Frattini R, Rossi P (2012) Report sulle donne nell’Università Italiana. Meno di zero, 3, 8-9.

Kanter RM (1977) Some effects of proportions on group life: Skewed sex ratios and responses to token women. American Journal of Sociology, 965-990.

Leibbrandt A, Wang LC and Foo C (2015) Gender Quotas, Competitions, and Peer Review: Experimental Evidence on the Backlash against Women. (No. 5526) CESifo Group Munich.

LERU (2015) Gender equality: we are definitely not there yet, Press Release.

Marini, G, and Meschitti, V (2018) The trench warfare of gender discrimination: evidence from academic promotions to full professor in Italy. Scientometrics, 115(2), 989-1006.

Meulders D, O’Dorchai SP (2013) She Figures 2012: Women and science: Statistics and Indicators. ULB Institutional Repository 2013/135739, ULB - Université Libre de Bruxelles.

Moss-Racusin CA, Dovidio JF, Brescoll VL, Graham MJ and Handelsman J (2012) Science faculty's subtle gender biases favor male students. Proceedings of the National Academy of Sciences, 109(41), 16474-16479.

Ridgeway CL (2009) Framed before we know it: How gender shapes social relations. Gender \& Society, 23(2), 145-160. 
Ridgeway CL, Correll SJ (2004) Unpacking the gender system: a theoretical perspective on gender beliefs and social relations. Gender \& Society, 18(4), 510-531.

Ridgeway CL and Kricheli-Katz T (2013) Intersecting cultural beliefs in social relations: Gender, race, and class binds and freedoms. Gender \& Society, 27(3), 294-318.

Sarah C, Mona LK (2008) Critical mass theory and women's political representation. Political Studies, 56(3), 725-736.

Shen H (2013). Mind the gender gap Nature, 495(7439), 22.

Van den Brink M, Benschop Y (2012a) Gender practices in the construction of academic excellence: Sheep with five legs. Organization, 19(4), 507-524.

Van den Brink M, Benschop Y (2012b) Slaying the seven-headed dragon; the quest for gender change. Gender, Work \& Organization, 19, 71-92.

Verbeek M (2008) A guide to modern econometrics. John Wiley \& Sons.

Witz A (1990) Patriarchy and professions: The gendered politics of occupational closure. Sociology, 24(4), 675-690.

Wold A, Wennerås C (1997) Nepotism and sexism in peer review. Nature, 387(6631), 341-343.

Wolfinger NH, Mason MA and Goulden M (2009) Stay in the game: Gender, family formation and alternative trajectories in the academic life course. Social Forces, 87(3), 1591-1621.

Zinovyeva N, Bagues M (2015) The role of connections in academic promotions. American Economic Journal: Applied Economics, 7(2), 264-292. 


\section{Tables}

Table 1 -Candidates and calls per year

\begin{tabular}{l|r|r}
\hline \multicolumn{1}{c}{ Year } & N. candidates & N. calls \\
\hline 2009 & 171 & 25 \\
2010 & 266 & 31 \\
2011 & 171 & 22 \\
\hline Total & 608 & 78 \\
\hline
\end{tabular}

Notes: Final sample.

Table 2 - Descriptive statistics - Candidates (means and s.d)

\begin{tabular}{|c|c|c|c|}
\hline Variables & $\begin{array}{c}\text { Entire } \\
\text { Sample }\end{array}$ & Female & Male \\
\hline Female & 0.20 & & \\
\hline Success & 0.14 & 0.16 & 0.14 \\
\hline \multirow[t]{2}{*}{ Age } & 30.49 & 29.94 & 30.62 \\
\hline & $(5.54)$ & $(4.74)$ & $(5.71)$ \\
\hline Italian (local) origin & 0.16 & 0.23 & 0.15 \\
\hline Italian (non-local) origin & 0.32 & 0.32 & 0.31 \\
\hline EU origin & 0.16 & 0.20 & 0.15 \\
\hline Non-EU origin & 0.37 & 0.25 & 0.40 \\
\hline \multirow[t]{2}{*}{ Publications (number of articles) } & 5.58 & 3.19 & 6.18 \\
\hline & $(21.05)$ & $(6.28)$ & $(23.28)$ \\
\hline \multirow[t]{2}{*}{ Publications adjusted for maternity risk } & 5.60 & 3.26 & 6.18 \\
\hline & $(21.06)$ & $(6.44)$ & $(23.28)$ \\
\hline \multirow[t]{2}{*}{$H$-index } & 1.33 & 0.85 & 1.45 \\
\hline & $(3.19)$ & $(1.55)$ & $(3.35)$ \\
\hline \multirow[t]{2}{*}{$H$-index adjusted for maternity risk } & 1.33 & 0.87 & 1.45 \\
\hline & $(3.09)$ & $(1.60)$ & $(3.35)$ \\
\hline \multirow[t]{2}{*}{ Work experience } & 4.45 & 3.61 & 4.66 \\
\hline & $(4.56)$ & $(3.72)$ & $(4.72)$ \\
\hline Field 1 (social sciences) & 0.07 & 0.16 & 0.05 \\
\hline Field 2 (hard sciences excluding math) & 0.33 & 0.34 & 0.33 \\
\hline Field 3 (engineering. computer sciences and math) & 0.59 & 0.50 & 0.62 \\
\hline Ties with the institute & 0.11 & 0.12 & 0.10 \\
\hline \multirow[t]{2}{*}{ Intensity of ties } & 1.35 & 1.13 & 1.42 \\
\hline & $(0.65)$ & $(0.35)$ & $(0.7)$ \\
\hline Institution ties & 0.74 & 0.87 & 0.70 \\
\hline Committee ties & 0.40 & 0.27 & 0.44 \\
\hline Male-Male ties & 69.2 & & \\
\hline Female-Male ties & 20.0 & & \\
\hline Undefined & 10.8 & & \\
\hline Sample size & 608 & 121 & 487 \\
\hline
\end{tabular}

Note: Different types of ties are only referred to the subsample of 65 observations of candidates with ties (15 female and 50 male candidates). 
Table 3-Descriptive statistics - Committee members (means and s.d)

\begin{tabular}{lrc} 
& Mean & s.d. \\
\hline At least one female (no HR) on committee & 0.17 & \\
Italian origin & 0.74 & \\
Age & 42.27 & 5.88 \\
Human resources & 0.58 & \\
H-index (no HR) & 7.81 & 7.14 \\
\hline
\end{tabular}

Note: The sample of committee members consists of 2,042 observations, of which 93 are unique. Descriptive statistics are computed at the call level.

Table 4 - Probability of success - Conditional logit (coefficients)

\begin{tabular}{|c|c|c|c|c|c|}
\hline Success & 1 & 2 & 3 & 4 & 5 \\
\hline Female & $\begin{array}{l}-0.033 \\
(0.309)\end{array}$ & $\begin{array}{l}-0.415 \\
(0.379)\end{array}$ & $\begin{array}{l}-0.369 \\
(0.383)\end{array}$ & $\begin{array}{l}-0.409 \\
(0.409)\end{array}$ & $\begin{array}{l}-0.433 \\
(0.445)\end{array}$ \\
\hline Female $\times$ Female (no HR) in Comm. & & $\begin{array}{l}1.587^{* *} \\
(0.760)\end{array}$ & $\begin{array}{l}1.525^{* *} \\
(0.762)\end{array}$ & $\begin{array}{l}1.500^{*} \\
(0.810)\end{array}$ & $\begin{array}{c}1.202 \\
(0.834)\end{array}$ \\
\hline H-index std. adj. & & & $\begin{array}{l}0.246^{* *} \\
(0.103)\end{array}$ & $\begin{array}{l}0.226^{* *} \\
(0.112)\end{array}$ & $\begin{array}{c}0.182 \\
(0.124)\end{array}$ \\
\hline Age & & & & $\begin{array}{c}0.053 \\
(0.283)\end{array}$ & $\begin{array}{l}-0.005 \\
(0.273)\end{array}$ \\
\hline Age squared & & & & $\begin{array}{c}-0.003 \\
(0.004)\end{array}$ & $\begin{array}{l}-0.002 \\
(0.004)\end{array}$ \\
\hline Italian (non-local) origin & & & & $\begin{array}{c}0.100 \\
(0.334)\end{array}$ & $\begin{array}{c}0.455 \\
(0.385)\end{array}$ \\
\hline EU origin & & & & $\begin{array}{l}-0.612 \\
(0.517)\end{array}$ & $\begin{array}{l}-0.207 \\
(0.564)\end{array}$ \\
\hline Non-EU origin & & & & $\begin{array}{c}-1.351^{* * * *} \\
(0.472)\end{array}$ & $\begin{array}{c}-1.219^{* *} \\
(0.508)\end{array}$ \\
\hline Ph.D. & & & & $\begin{array}{c}0.648 \\
(0.399)\end{array}$ & $\begin{array}{c}0.505 \\
(0.434)\end{array}$ \\
\hline Work experience & & & & $\begin{array}{l}0.110^{* *} \\
(0.046)\end{array}$ & $\begin{array}{l}0.124^{* *} \\
(0.048)\end{array}$ \\
\hline Ties with the institute & & & & & $\begin{array}{l}1.735^{* * *} \\
(0.386)\end{array}$ \\
\hline $\begin{array}{l}\text { Pseudo } \mathrm{R}^{2} \\
\text { Observations }\end{array}$ & $\begin{array}{c}0.000 \\
606\end{array}$ & $\begin{array}{c}0.016 \\
606\end{array}$ & $\begin{array}{c}0.034 \\
606\end{array}$ & $\begin{array}{c}0.119 \\
606\end{array}$ & $\begin{array}{c}0.194 \\
606\end{array}$ \\
\hline
\end{tabular}

Notes: Standard errors in parentheses $(* * * \mathrm{p}<0.01, * * \mathrm{p}<0.05, * \mathrm{p}<0.1)$. Italian (local) origin used as reference category. 
Table 5 - Probability of success in different sample splits - Conditional logit (coefficients)

\begin{tabular}{|c|c|c|c|c|c|c|c|c|}
\hline Success & $1 \mathrm{a}$ & $1 \mathrm{~b}$ & $2 \mathrm{a}$ & $2 b$ & $3 a$ & $3 \mathrm{~b}$ & $4 a$ & $4 \mathrm{~b}$ \\
\hline & \multicolumn{4}{|c|}{ H-index committee: } & \multicolumn{4}{|c|}{ Position: } \\
\hline & \multicolumn{2}{|c|}{$4^{\text {th }}$ quartile } & \multicolumn{2}{|c|}{$1^{\text {st }}-3^{\text {rd }}$ quartiles } & \multicolumn{2}{|c|}{ Non-tenure-track } & \multicolumn{2}{|c|}{ Tenure-track } \\
\hline Female & -0.340 & -0.190 & -0.350 & -0.335 & $-1.127 *$ & $-1.453 * *$ & 0.560 & 0.785 \\
\hline Female $\times$ Female (no & $(1.189)$ & $(1.242)$ & $(0.436)$ & $(0.471)$ & $(0.628)$ & $(0.698)$ & $(0.603)$ & $(0.635)$ \\
\hline \multirow[t]{2}{*}{$H R$ ) in Comm. } & & & 1.211 & 0.726 & $2.082 * *$ & $1.999 *$ & 0.979 & 0.426 \\
\hline & & & $(0.837)$ & $(0.871)$ & $(1.018)$ & $(1.063)$ & $(1.456)$ & $(1.676)$ \\
\hline \multirow[t]{2}{*}{ H-index std. adj. } & $0.308^{*}$ & $0.342 *$ & 0.165 & 0.159 & $0.439 * *$ & $0.482 * * *$ & 0.106 & 0.022 \\
\hline & $(0.159)$ & $(0.190)$ & $(0.201)$ & $(0.222)$ & $(0.183)$ & $(0.183)$ & $(0.175)$ & $(0.180)$ \\
\hline \multirow[t]{2}{*}{ Age } & 0.767 & 0.822 & 0.034 & -0.043 & -0.026 & -0.087 & 0.110 & -0.037 \\
\hline & $(1.451)$ & $(1.466)$ & $(0.291)$ & $(0.276)$ & $(0.355)$ & $(0.349)$ & $(0.585)$ & $(0.514)$ \\
\hline \multirow[t]{2}{*}{ Age squared } & -0.014 & -0.015 & -0.002 & -0.001 & -0.002 & -0.001 & -0.003 & -0.001 \\
\hline & $(0.023)$ & $(0.023)$ & $(0.004)$ & $(0.004)$ & $(0.006)$ & $(0.005)$ & $(0.009)$ & $(0.007)$ \\
\hline \multirow[t]{2}{*}{ Italian origins } & $1.982 * *$ & $1.970 * *$ & $0.997 * * *$ & $0.991 * *$ & $0.945 * *$ & $0.933 * *$ & $1.679 * *$ & $2.115^{* * *}$ \\
\hline & $(0.863)$ & $(0.867)$ & $(0.380)$ & $(0.401)$ & $(0.413)$ & $(0.430)$ & $(0.708)$ & $(0.803)$ \\
\hline \multirow[t]{2}{*}{ Ph.D. } & 0.324 & 0.234 & $0.752 *$ & 0.608 & 0.682 & 0.721 & 0.839 & 0.441 \\
\hline & $(1.267)$ & $(1.285)$ & $(0.424)$ & $(0.468)$ & $(0.563)$ & $(0.601)$ & $(0.567)$ & $(0.652)$ \\
\hline \multirow[t]{2}{*}{ Work experience } & $0.321 * *$ & $0.334 * *$ & $0.083^{*}$ & $0.097 *$ & $0.127 * *$ & $0.142 * * *$ & 0.062 & 0.086 \\
\hline & $(0.156)$ & $(0.162)$ & $(0.049)$ & $(0.052)$ & $(0.054)$ & $(0.055)$ & $(0.099)$ & $(0.104)$ \\
\hline \multirow[t]{2}{*}{ Ties with the institute } & & -0.552 & & $1.699 * * *$ & & $1.642 * * *$ & & $2.108 * * *$ \\
\hline & & $(1.719)$ & & $(0.384)$ & & $(0.499)$ & & $(0.610)$ \\
\hline Pseudo $\mathrm{R}^{2}$ & 0.242 & 0.244 & 0.098 & 0.190 & 0.137 & 0.198 & 0.152 & 0.282 \\
\hline Observations & 168 & 168 & 438 & 438 & 417 & 417 & 189 & 189 \\
\hline
\end{tabular}

Notes: Standard errors in parentheses $(* * * \mathrm{p}<0.01, * * \mathrm{p}<0.05, * \mathrm{p}<0.1)$. In models $1 \mathrm{a}$ and $1 \mathrm{~b}$ the interaction term is not included due to the existence of just one mixed-gender committee belonging to the $4^{\text {th }}$ quartile of committees in terms of $\mathrm{H}$-index distribution. Due to small number of cases in sample splits, geographical origin is given as being of Italian origin or not. 
Table 6-Probability of success - Conditional logit (coefficients) - Low vs. high wage positions

\begin{tabular}{lcccc}
\hline Success & & Low-wage & High-wage \\
Female & -1.025 & $-1.522^{*}$ & -0.015 & 0.003 \\
& $(0.657)$ & $(0.815)$ & $(0.579)$ & $(0.590)$ \\
Female $\times$ Female (no HR) in Comm. & 0.887 & 0.199 & 15.83 & 16.906 \\
& $(1.155)$ & $(1.301)$ & $(992.7)$ & $(1666.733)$ \\
H-index std. adj. & -0.747 & -0.943 & $0.243^{* *}$ & $0.220^{*}$ \\
& $(0.633)$ & $(0.715)$ & $(0.113)$ & $(0.119)$ \\
Age & 0.924 & 0.452 & 0.130 & 0.126 \\
& $(0.728)$ & $(0.714)$ & $(0.324)$ & $(0.323)$ \\
Age squared & -0.019 & -0.011 & -0.003 & -0.003 \\
& $(0.012)$ & $(0.012)$ & $(0.005)$ & $(0.005)$ \\
Italian origins & $1.322^{* *}$ & $1.353^{* *}$ & $1.214 * *$ & $1.284^{* *}$ \\
Ph.D. & $(0.514)$ & $(0.579)$ & $(0.522)$ & $(0.527)$ \\
Work experience & $1.003^{*}$ & 0.982 & 0.866 & 0.714 \\
Ties with the institute & $(0.570)$ & $(0.642)$ & $(0.691)$ & $(0.711)$ \\
& 0.127 & $0.176^{*}$ & $0.103^{*}$ & $0.106^{*}$ \\
Pseudo R ${ }^{2}$ & $(0.086)$ & $(0.100)$ & $(0.056)$ & $(0.056)$ \\
Observations & & & 0.739 \\
\hline
\end{tabular}

Notes: Standard errors in parentheses $(* * * \mathrm{p}<0.01, * * \mathrm{p}<0.05, * \mathrm{p}<0.1)$. Italian (local) origin used as reference category.

Table 7 - Probability of success - Conditional logit (coefficients) with types, intensity of ties and gendered ties

\begin{tabular}{lcccc}
\hline Success & 1 & 2 & 3 & 4 \\
\hline & & & & \\
Female & -0.409 & -0.573 & -0.304 & -0.303 \\
& $(0.409)$ & $(0.477)$ & $(0.437)$ & $(0.512)$ \\
Female $\times$ Female (no HR) in Comm. & $1.500^{*}$ & $1.545^{*}$ & 1.052 & 1.241 \\
& $(0.810)$ & $(0.892)$ & $(0.843)$ & $(0.862)$ \\
Institution ties & & $2.385^{* * *}$ & & \\
Committee ties & $(0.465)$ & & \\
& & -0.116 & & \\
Intensity of ties & $(0.743)$ & & \\
& & & $1.340^{* * *}$ & \\
Male-Male ties & & & $(0.310)$ & $1.990^{* * *}$ \\
Female-Male ties & & & & $(0.483)$ \\
& & & & $\left(.524^{* *}\right.$ \\
Undefined & & & & $0.761)$ \\
CONTROLS & & & & $(1.224)$ \\
Pseudo R & & & & YES \\
Observations & YES & YES & YES & 0.198 \\
\hline
\end{tabular}

Notes: Standard errors in parentheses $(* * * \mathrm{p}<0.01, * * \mathrm{p}<0.05, * \mathrm{p}<0.1)$ Controls include: H-index std., Age, Age squared, Geographical origins, Ph.D., Work experience. 
${ }^{\mathrm{i}}$ Confidentiality issues have been dealt with according to the Italian personal data protection code (Legislative Decree no. 196 of 30 June 2003), since all candidates by law had to agree to it with a declaration reported on their CVs.

ii More information on the procedure is in the appendix.

iii The analyses were also run with the standardized number of publications instead of the H-index without any relevant change in results.

${ }^{\text {iv }}$ Although the focus of our analysis is on the presence of gender bias, similar mechanisms might be operating for people belonging to different minority groups, of various sexual identities and so on. The analysis of selections in the institute shows that bias based on non-European origin might be worth future investigation.

${ }^{\mathrm{v}}$ The scientific productivity of the committee is the mean of the scientific productivity of participating committee members, which is computed according to Scopus data base.

${ }^{\text {vi }}$ The table is available upon request. 


\section{Appendix}

\section{Data}

The data collected include information on 664 candidates for 111 calls posted between 2009 and 2011. The number of calls follows an irregular time profile over the years: 36 calls were posted in 2009, 47 in 2010 and 28 in 2011. The number of applications follows a similar pattern: 183 candidates were examined in 2009, 290 candidates in 2010 and 191 candidates in 2011. Some of these competitions failed to fill the position, while a few resulted in the recruitment of more than one candidate. For 27 competitions, only one application was received and these were excluded from the final sample. Candidates applied online or via email, and their applications are kept by the institution for up to 5 years. The administrative archives hold the official final reports with the results of each opening as well as the job advertisement contained in the public call.

The final data set used in the analyses comprises 78 calls: 171 candidates for 25 calls posted in 2009, 266 candidates for 31 calls in 2010, and 171 candidates for 22 calls referred to 2011. Out of the 78 calls, 72 resulted in the recruitment of one candidate, and these account for 502 candidates, whereas five calls led to two recruitments, and one led to three, with 73 and 33 applicants respectively.

\section{Control variables}

Age is a continuous variable. The candidate's age is missing in $47 \%$ of the CVs. When no age is reported, it is estimated from the year of graduation. Origin was coded distinguishing between region where the institute is placed (local), the rest of Italy, the European Union (including Switzerland) and the rest of the world.

Several variables show the research potential of the candidates. Educational attainment consists of four categories: no degree, bachelor's degree, master's and Ph.D.'s. Since the positions advertised 
at the institute are research positions that usually require a doctoral degree, a dummy variable Ph.D. ( 1 if the candidate holds a Ph.D. and 0 otherwise) is used to represent educational attainment in the models.

Years of work experience (research and non-research related activities) are included in the analysis; Ph.D. activity alone is not considered as work experience, whereas lecturing and/or other types of employment, even if undertaken during the Ph.D., are taken into account.

The data set also includes information on the candidates' scientific output. Candidates self-reported their publications in their CVs. Nevertheless, in order to standardise the comparison within and between competitions, the data regarding the number of publications and citations were directly retrieved from Scopus, Elsevier's bibliographic database created in 2004. In order to obtain the applicants' publication records, the Scopus Author search page was queried with the researchers' first and last names. If the author's name was not unique, the results were cross-checked with data appearing on the candidate's CV, such as age, origin and field of study, in order to refine the results and ensure a correct attribution of publications to candidates. The Scopus database was accessed in August 2014. Although other bibliographic sources such as Google Scholar and Web of Science are available, many studies suggest that Scopus is superior in terms of both coverage and accuracy. According to Falagas et al. (2008, p. 338), "Scopus offers about 20\% more coverage than Web of Science, whereas Google Scholar offers results of inconsistent accuracy." Moreover, "Scopus helps distinguish between the researchers in a more nuanced fashion than Web of Science." (Meho and Rogers, 2008, p. 1711). Both publications and H-index data were retrieved for the specific year of the call for which the candidate applied. The candidates' H-index was collected in addition to the number of publications, since it combines measures of quantity and visibility of scientific production, and therefore is a good proxy for the importance and significance of candidates' contributions (Hirsch, 2005). However, in order to take into account the different publication propensities across disciplines, we implemented a standardization of H-index within: i) social 
sciences correlated to engineering research areas (like management, human resources); ii) hard sciences excluding mathematics, iii) engineering, computer sciences, architecture, environmental sciences and mathematics.

The H-index is then adjusted for maternity risk. We obtained data regarding fertility of female researchers from the HR department of the institute. The maternity rate in the institute is very low (only one woman out of four has ever had children), and the average age of mother at the first child is 35 years old. Adjusted standardized $\mathrm{H}$-index has been computed as follows: $H$ index std.adj. $=$ $\frac{\text { Hindex }_{\text {std. }}}{(1-\text { maternity risk })}$.

\section{Table A1 - Variable definitions}

\begin{tabular}{|c|c|c|}
\hline Variable & Dummy & Definition \\
\hline Female & $\mathrm{D}$ & The candidate is female \\
\hline Success & $\mathrm{D}$ & The candidate is recruited \\
\hline $\begin{array}{l}\text { Female (no HR) on } \\
\text { committee }\end{array}$ & $\mathrm{D}$ & $\begin{array}{r}\text { The candidate is evaluated by a committee with at least one female } \\
\text { researcher (no HR) }\end{array}$ \\
\hline $\begin{array}{l}\text { H-index standardized } \\
\text { adjusted }\end{array}$ & & $\begin{array}{r}\text { Candidate's H-index at the year of the call, standardized by applicants' } \\
\text { field of research and adjusted for maternity risk }\end{array}$ \\
\hline Age & & Candidate's age in years \\
\hline Italian local origin & $\mathrm{D}$ & $\begin{array}{l}\text { The candidate has Italian nationality and local origin (from the } \\
\text { Trentino-Alto Adige region where the institute is located) }\end{array}$ \\
\hline $\begin{array}{l}\text { Italian non-local } \\
\text { origin }\end{array}$ & $\mathrm{D}$ & $\begin{array}{l}\text { The candidate has Italian nationality and non-local origin (outside the } \\
\text { Trentino-Alto Adige region where the institute is located) }\end{array}$ \\
\hline EU origin & $\mathrm{D}$ & The candidate has an EU nationality (including Switzerland) \\
\hline Non-EU origin & $\mathrm{D}$ & The candidate has a non-EU nationality \\
\hline Ph.D. & D & The candidate holds a Ph.D. \\
\hline Work experience & & Candidate's work experience in years, excluding Ph.D. years \\
\hline Ties with the institute & $\mathrm{D}$ & $\begin{array}{r}\text { The candidate has at least one among the types of ties indicated at } \\
\text { Section 4.1.1 }\end{array}$ \\
\hline Ties with committee & $\mathrm{D}$ & $\begin{array}{r}\text { The candidate has ties with the institute either of type } 1), 2 \text { ) or } 5 \text { ) - see } \\
\text { main text }\end{array}$ \\
\hline Ties with institution & $\mathrm{D}$ & $\begin{array}{r}\text { The candidate has ties with the institute either of type } 3 \text { ) or } 4 \text { ) - see } \\
\text { main text }\end{array}$ \\
\hline Intensity of ties & & Number of candidate's types of ties with the institute (range $0-5$ ) \\
\hline Male-Male ties & $\mathrm{D}$ & male and has a tie with a male \\
\hline Female-Male tie & $\mathrm{D}$ & The candidate is a female and has a tie with a male \\
\hline Undefined & $\mathrm{D}$ & The gender of the candidates' contact is not observable \\
\hline Tenure-track positions & $\mathrm{D}$ & R3, R4 positions \\
\hline $\begin{array}{l}\text { Non tenure-track } \\
\text { positions }\end{array}$ & $\mathrm{D}$ & T4, post-doc, or co.co.pro. positions \\
\hline Monthly wage & & \\
\hline & & tract length of the posted position expressed in months \\
\hline
\end{tabular}

\section{Descriptive statistics}


Descriptive statistics regarding the monthly wage, the applicants' ages and the contract length across the different research positions are reported in Table A2.

Table A2 - Descriptive statistics of research levels

\begin{tabular}{|c|c|c|c|c|}
\hline Variable & Mean & Std. Dev. & Min & $\operatorname{Max}$ \\
\hline Monthly wage (all) & 2687 & 905.23 & 750 & 4388 \\
\hline$R 3$ & 3113 & 124.32 & 2667 & 3156 \\
\hline$R 4$ & 2842 & 124.22 & 2750 & 3150 \\
\hline$T 4$ & 2750 & 0 & 2750 & 2750 \\
\hline Post-doc & 3156 & 0 & 3156 & 3156 \\
\hline Co.co.pro. & 2394 & 815.45 & 750 & 4388 \\
\hline Applicant's age (all) & 30.65 & 5.77 & 19 & 60 \\
\hline$R 3$ & 32.94 & 5.43 & 26 & 55 \\
\hline$R 4$ & 30.65 & 5.30 & 24 & 56 \\
\hline$T 4$ & 26.59 & 5.38 & 20 & 37 \\
\hline Post-doc & 32.33 & 3.24 & 26 & 37 \\
\hline Co.co.pro. & 30.17 & 5.54 & 19 & 60 \\
\hline $\begin{array}{r}\text { Contract length in } \\
\text { months (all) }\end{array}$ & 21.46 & 11.01 & 3 & 44 \\
\hline$R 3$ & 29.63 & 9.12 & 12 & 42 \\
\hline$R 4$ & 25.58 & 9.41 & 8 & 36 \\
\hline T4 & 8.36 & 1.18 & 8 & 12 \\
\hline Post-doc & 30.40 & 6.20 & 24 & 36 \\
\hline Co.co.pro. & 18.83 & 10.50 & 3 & 44 \\
\hline
\end{tabular}

Table A3 depicts the number of candidates and calls across the different positions included in the data set. There are on average 8 applications per call ( 7.27 for tenure-track positions and 8.06 for non-tenure-track positions). The variation in the number of candidates across calls, however, is considerable, ranging from 2 applicants to more than 30 applicants. Majority of calls are for nontenure-track positions (69\%). The percentage of female candidates does not differ between tenuretrack and non-tenure-track positions. However, the success rate of the female candidates is higher in tenure-track applications. 
Table A3 - Number of candidates and calls across different positions

\begin{tabular}{|c|c|c|c|c|c|}
\hline Position & $\begin{array}{c}N . \\
\text { candidates }\end{array}$ & N. calls & $\begin{array}{c}\text { Average } N . \\
\text { of } \\
\text { candidates } \\
\text { per call } \\
\end{array}$ & $\begin{array}{l}\% \text { offemale } \\
\text { candidates }\end{array}$ & $\begin{array}{c}\text { Success } \\
\text { rate of } \\
\text { female } \\
\text { candidates }\end{array}$ \\
\hline Tenure-track & 189 & 26 & 7.27 & 0.20 & 0.22 \\
\hline$R 3$ & 65 & 13 & 5.00 & & \\
\hline$R 4$ & 124 & 13 & 9.54 & & \\
\hline Non-Tenure-track & 419 & 52 & 8.06 & 0.20 & 0.13 \\
\hline$T 4$ & 22 & 2 & 11.00 & & \\
\hline Post-doc & 15 & 2 & 7.50 & & \\
\hline Co.co.pro. & 382 & 48 & 7.96 & & \\
\hline Total & 608 & 78 & 7.80 & 0.20 & 0.20 \\
\hline
\end{tabular}

By breaking down the variable representing prior ties with the institute into "institution" and "committee" ties, it is shown that female candidates have disproportionally fewer ties with the committee than their male counterparts. Similarly, intensity of ties is higher for male candidates (Table A4).

Table A4 - Breaking down of ties with the institute

\begin{tabular}{lrrr} 
& Institution & Committee & $\begin{array}{c}\text { Intensity of } \\
\text { ties (1-5) }\end{array}$ \\
\hline Females & $27.08 \%$ & $15.38 \%$ & 1.13 \\
\hline Males & $72.92 \%$ & $84.62 \%$ & 1.42 \\
\hline Total & $100 \%$ & $100 \%$ & 1.35 \\
\hline
\end{tabular}

Notes: Candidates with at least one tie amount to 65 , of which 15 are females and 50 males.

Table A5 shows that out of 65 observations with prior ties (11\% of the final sample), $69.2 \%$ of these are male-male direct connections, $20 \%$ are female-male connections and $10.8 \%$ are undefined.

Table A5-Gendered ties

\begin{tabular}{lr} 
& $\%$ \\
\hline Female-Female tie & 0 \\
\hline Female-Male tie & 20 \\
\hline Male-Female tie & 0 \\
\hline Male-Male tie & 69.2 \\
\hline Undefined & 10.8 \\
\hline Total & 100 \\
\hline
\end{tabular}




\section{Empirical analyses}

All models were also estimated replacing the standardized $\mathrm{H}$-index of candidates with the standardized number of publications at the year of the competition, without differences in terms of sign and statistical significance of the relevant coefficients. Moreover, the results of the final conditional logit models are mostly confirmed in significance and in signs when linear probability model estimation is performed.

Table A6 reports the full results of a linear probability model, with fixed effects at the call level, which represents the main model specification of Table 4 in the main text.

Table A6 - Probability of success - Linear probability model

\begin{tabular}{|c|c|c|c|c|c|}
\hline Success & 1 & 2 & 3 & 4 & 5 \\
\hline Female & $\begin{array}{l}-0.004 \\
(0.043)\end{array}$ & $\begin{array}{l}-0.054 \\
(0.048)\end{array}$ & $\begin{array}{l}-0.046 \\
(0.048)\end{array}$ & $\begin{array}{l}-0.048 \\
(0.049)\end{array}$ & $\begin{array}{l}-0.038 \\
(0.048)\end{array}$ \\
\hline Female $\times$ Female $($ no HR) in Comm. & & $\begin{array}{l}0.205^{* *} \\
(0.090)\end{array}$ & $\begin{array}{l}0.197^{* *} \\
(0.089)\end{array}$ & $\begin{array}{l}0.175^{*} \\
(0.089)\end{array}$ & $\begin{array}{c}0.138 \\
(0.092)\end{array}$ \\
\hline$H$-index std. adj. & & & $\begin{array}{c}0.037^{*} \\
(0.021)\end{array}$ & $\begin{array}{c}0.027 \\
(0.019)\end{array}$ & $\begin{array}{c}0.021 \\
(0.020)\end{array}$ \\
\hline Age & & & & $\begin{array}{l}-0.005 \\
(0.015)\end{array}$ & $\begin{array}{l}-0.011 \\
(0.015)\end{array}$ \\
\hline Age squared & & & & $\begin{array}{l}-0.000 \\
(0.000)\end{array}$ & $\begin{array}{l}-0.000 \\
(0.000)\end{array}$ \\
\hline Italian non-local origin & & & & $\begin{array}{c}0.002 \\
(0.064)\end{array}$ & $\begin{array}{c}0.046 \\
(0.060)\end{array}$ \\
\hline EU origin & & & & $\begin{array}{l}-0.092 \\
(0.063)\end{array}$ & $\begin{array}{l}-0.049 \\
(0.059)\end{array}$ \\
\hline Non-EU origin & & & & $\begin{array}{l}-0.143^{* * *} \\
(0.062)\end{array}$ & $\begin{array}{l}-0.117^{* * *} \\
(0.058)\end{array}$ \\
\hline Ph.D. & & & & $\begin{array}{l}0.109^{* * *} \\
(0.045)\end{array}$ & $\begin{array}{l}0.087^{*} \\
(0.044)\end{array}$ \\
\hline Work experience & & & & $\begin{array}{l}0.011^{* * *} \\
(0.005)\end{array}$ & $\begin{array}{l}0.012^{* *} \\
(0.005)\end{array}$ \\
\hline Ties with the institute & & & & & $\begin{array}{l}0.313^{* * *} \\
(0.083)\end{array}$ \\
\hline $\mathrm{R}^{2}$ & 0.135 & 0.143 & 0.153 & 0.190 & 0.249 \\
\hline Observations & 608 & 608 & 608 & 608 & 608 \\
\hline
\end{tabular}

Notes: The Table reports linear probability model coefficients, with call fixed effects. The dependent variable is a dummy variable for being recruited. Clustered standard errors (at the call level) are reported in parenthesis. Symbols *, $* *$ and $* * *$ indicate that the coefficients are statistically significant at the $10 \%, 5 \%$ and $1 \%$ levels, respectively. Italian local origin used as reference category. 608 observations (in contrast to 606 is the conditional logit) due to difference in estimation procedures. 
Table A7 reports the results of a linear probability model, with fixed effects at the call level, for sample splits as in Table 5 in the main article.

Table A7 - Probability of success in different sample splits - Linear probability model

\begin{tabular}{|c|c|c|c|c|c|c|c|c|}
\hline \multirow[t]{3}{*}{ Success } & $1 \mathrm{a}$ & $1 \mathrm{~b}$ & $2 a$ & $2 b$ & $3 a$ & $3 \mathrm{~b}$ & $4 a$ & $4 \mathrm{~b}$ \\
\hline & \multicolumn{4}{|c|}{ H-index commission: } & \multicolumn{4}{|c|}{ Position: } \\
\hline & \multicolumn{2}{|c|}{$4^{\text {th }}$ quartile } & \multicolumn{2}{|c|}{$1^{\text {st }}-3^{\text {rd }}$ quartiles } & \multicolumn{2}{|c|}{ Non-tenure-track } & \multicolumn{2}{|c|}{ Tenure-track } \\
\hline Female & $\begin{array}{c}-0.015 \\
(0.043)\end{array}$ & $\begin{array}{c}-0.015 \\
(0.044)\end{array}$ & $\begin{array}{c}-0.048 \\
(0.067)\end{array}$ & $\begin{array}{c}-0.036 \\
(0.065)\end{array}$ & $\begin{array}{c}-0.102^{* * *} \\
(0.049)\end{array}$ & $\begin{array}{l}-0.093^{*} \\
(0.052)\end{array}$ & $\begin{array}{c}0.083 \\
(0.091)\end{array}$ & $\begin{array}{c}0.092 \\
(0.082)\end{array}$ \\
\hline Female $\times$ Female (no HR) in Comm. & $\begin{array}{c}0.485^{* * * *} \\
(0.065)\end{array}$ & $\begin{array}{c}0.485^{* * * *} \\
(0.066)\end{array}$ & $\begin{array}{c}0.145 \\
(0.106)\end{array}$ & $\begin{array}{c}0.100 \\
(0.109)\end{array}$ & $\begin{array}{l}0.229^{* * *} \\
(0.098)\end{array}$ & $\begin{array}{l}0.189^{*} \\
(0.104)\end{array}$ & $\begin{array}{c}0.085 \\
(0.186)\end{array}$ & $\begin{array}{c}0.054 \\
(0.196)\end{array}$ \\
\hline H-index std. adj. & $\begin{array}{c}0.033 \\
(0.025)\end{array}$ & $\begin{array}{c}0.033 \\
(0.025)\end{array}$ & $\begin{array}{c}0.020 \\
(0.033)\end{array}$ & $\begin{array}{c}0.021 \\
(0.031)\end{array}$ & $\begin{array}{c}0.052 \\
(0.036)\end{array}$ & $\begin{array}{c}0.053 \\
(0.035)\end{array}$ & $\begin{array}{c}0.009 \\
(0.010)\end{array}$ & $\begin{array}{l}-0.004 \\
(0.009)\end{array}$ \\
\hline Age & $\begin{array}{c}0.004 \\
(0.020)\end{array}$ & $\begin{array}{c}0.004 \\
(0.020)\end{array}$ & $\begin{array}{l}-0.008 \\
(0.019)\end{array}$ & $\begin{array}{l}-0.014 \\
(0.018)\end{array}$ & $\begin{array}{l}-0.011 \\
(0.018)\end{array}$ & $\begin{array}{l}-0.017 \\
(0.018)\end{array}$ & $\begin{array}{l}-0.003 \\
(0.032)\end{array}$ & $\begin{array}{l}-0.006 \\
(0.033)\end{array}$ \\
\hline Age squared & $\begin{array}{l}-0.000 \\
(0.000)\end{array}$ & $\begin{array}{c}-0.000 \\
(0.000)\end{array}$ & $\begin{array}{l}-0.000 \\
(0.000)\end{array}$ & $\begin{array}{c}0.000 \\
(0.000)\end{array}$ & $\begin{array}{l}-0.000 \\
(0.000)\end{array}$ & $\begin{array}{c}0.000 \\
(0.000)\end{array}$ & $\begin{array}{l}-0.000 \\
(0.000)\end{array}$ & $\begin{array}{l}-0.000 \\
(0.000)\end{array}$ \\
\hline Italian origins & $\begin{array}{c}0.103 \\
(0.082)\end{array}$ & $\begin{array}{c}0.103 \\
(0.078)\end{array}$ & $\begin{array}{l}0.133^{* * *} \\
(0.053)\end{array}$ & $\begin{array}{l}0.122^{* * *} \\
(0.054)\end{array}$ & $\begin{array}{l}0.100^{*} \\
(0.052)\end{array}$ & $\begin{array}{l}0.099^{*} \\
(0.052)\end{array}$ & $\begin{array}{c}0.189^{* * * *} \\
(0.067)\end{array}$ & $\begin{array}{l}0.186^{* * *} \\
(0.072)\end{array}$ \\
\hline Ph.D. & $\begin{array}{c}0.017 \\
(0.022)\end{array}$ & $\begin{array}{c}0.017 \\
(0.021)\end{array}$ & $\begin{array}{l}0.148^{* * *} \\
(0.065)\end{array}$ & $\begin{array}{c}0.104 \\
(0.067)\end{array}$ & $\begin{array}{c}0.088 \\
(0.054)\end{array}$ & $\begin{array}{c}0.088 \\
(0.059)\end{array}$ & $\begin{array}{c}0.140^{*} \\
(0.080)\end{array}$ & $\begin{array}{c}0.083 \\
(0.075)\end{array}$ \\
\hline Work experience & $\begin{array}{l}0.014^{*} \\
(0.007)\end{array}$ & $\begin{array}{l}0.014^{*} \\
(0.007)\end{array}$ & $\begin{array}{l}0.011^{*} \\
(0.006)\end{array}$ & $\begin{array}{c}0.012^{*} \\
(0.006)\end{array}$ & $\begin{array}{l}0.012^{*} \\
(0.007)\end{array}$ & $\begin{array}{l}0.014^{* *} \\
(0.007)\end{array}$ & $\begin{array}{c}0.009 \\
(0.008)\end{array}$ & $\begin{array}{c}0.009 \\
(0.008)\end{array}$ \\
\hline Ties with the institute & & $\begin{array}{c}-0.001 \\
(0.235)\end{array}$ & & $\begin{array}{c}0.341^{* * * *} \\
(0.093)\end{array}$ & & $\begin{array}{l}0.263^{* *} \\
(0.112)\end{array}$ & & $\begin{array}{c}0.377^{* * * *} \\
(0.130) \\
\end{array}$ \\
\hline$\overline{\mathrm{R}^{2}}$ & 0.160 & 0.160 & 0.183 & 0.257 & 0.215 & 0.253 & 0.170 & 0.273 \\
\hline Observations & 168 & 168 & 440 & 440 & 419 & 419 & 189 & 189 \\
\hline
\end{tabular}

Notes: The Table reports linear probability coefficients, with call fixed effects. The dependent variable is a dummy variable for being recruited. Clustered standard errors (at the call level) are reported in parenthesis. In models $1 \mathrm{a}$ and $1 \mathrm{~b}$ the interaction term is not included due to the existence of just one mixed-gender commission belonging to the $4^{\text {th }}$ quartile of commissions in terms of $\mathrm{H}$-index std. Due to small number of cases in sample splits, geographical origin is given as being of Italian origin or not. Symbols *, ** and *** indicate that the coefficients are statistically significant at the $10 \%, 5 \%$ and $1 \%$ levels, respectively.

Finally, Table A8 contains estimations from a linear probability model which parallel those of

Table 6 in the main text for a conditional logit. 
Table A 8 - Probability of success - Linear probability model - Low vs. high wage positions

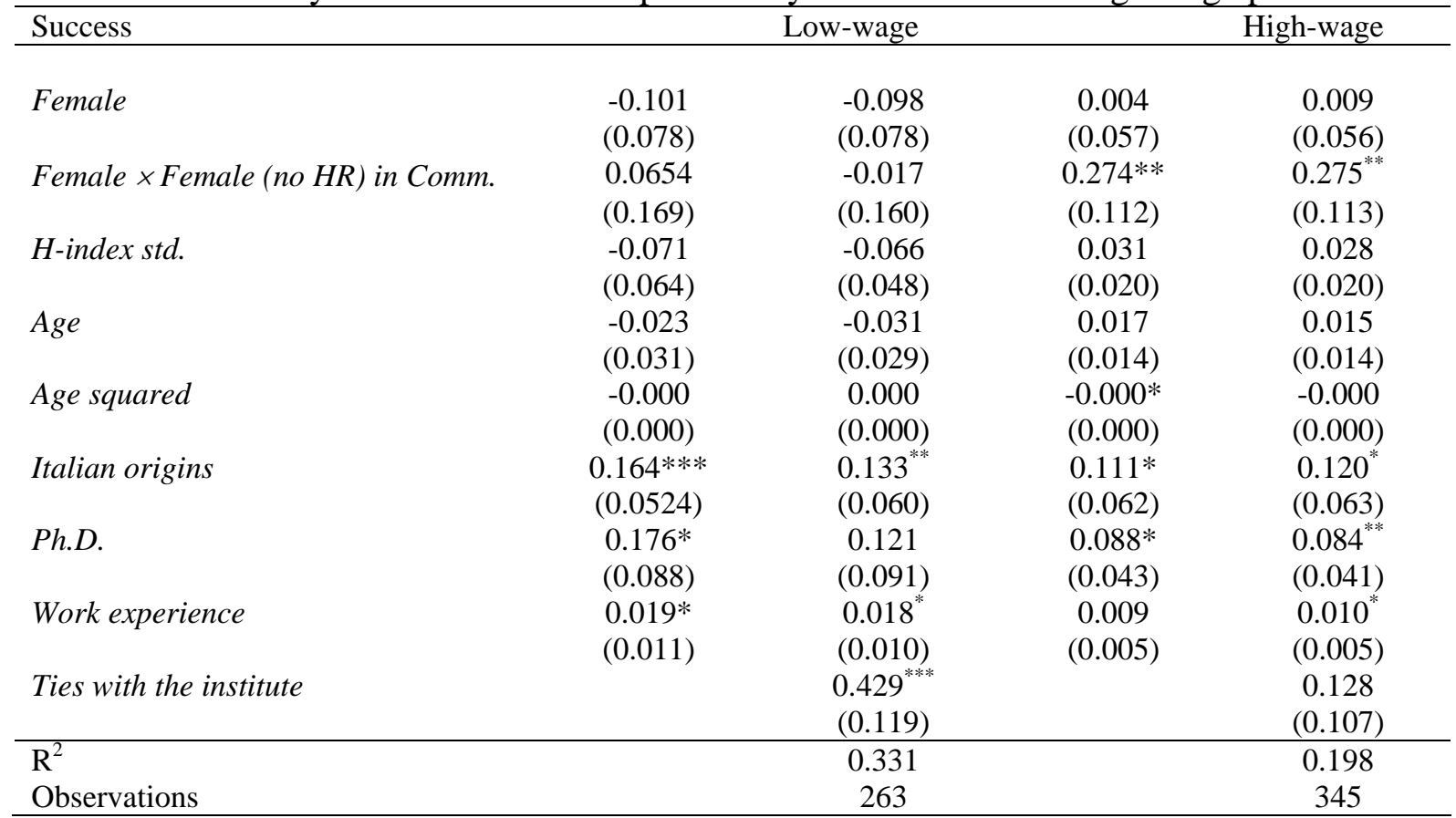

Notes: Standard errors in parentheses $(* * * \mathrm{p}<0.01, * * \mathrm{p}<0.05, * \mathrm{p}<0.1)$. Italian (local) origin used as reference category.

\section{Gender, ties and recruitment}

Table A9 reports the percentage of candidates with and without prior ties: overall, $12.40 \%$ of the female applicants have previous ties with the institute, and the percentage for males stands at $10.27 \%$ (the differences in the proportions are not statistically significant; two-group test of proportions: $\mathrm{z}=-0.599, \mathrm{p}=0.549)$. No statistically significant differences across genders were found when successful and unsuccessful applicants were considered separately.

Table A9 - Gender composition of successful and unsuccessful candidates

\begin{tabular}{rrrrr} 
& Females & $\%$ & Males & $\%$ \\
\hline Overall & & & & \\
Ties & 15 & $12.40 \%$ & 50 & $10.27 \%$ \\
No ties & 106 & $87.60 \%$ & 437 & $89.73 \%$ \\
Successful & & & & \\
Ties & 6 & $31.58 \%$ & 22 & $33.33 \%$ \\
No ties & 13 & $68.42 \%$ & 44 & $66.67 \%$ \\
Unsuccessful & & & & \\
Ties & 9 & $8.82 \%$ & 28 & $6.65 \%$ \\
No ties & 93 & $91.18 \%$ & 393 & $93.35 \%$ \\
\hline
\end{tabular}


Table A10 reports the predicted probabilities of success for female and male candidates with different profiles, net of other characteristics, computed from estimated coefficients of the main model with two-way and three-way interactions (gender of the candidate, woman on the committee, prior ties). Male candidates have a $40 \%$ probability of success without prior ties, and $76 \%$ with prior ties. Female candidates with ties and all-male committees have a 55\% probability of winning a selection. The probability is very high, at $91 \%$, if female candidates are both connected and there is a female researcher on the selection committee. Moreover, in $50 \%$ of the competitions in which female candidates with a prior connection were successful there was at least one female researcher on the committee.

Table A10. Conditional logit with 1) interaction between the gender of the candidates and prior ties, and 2) interaction between the gender of the candidates, the presence of women on the committee and prior ties. Predicted probabilities of success

\begin{tabular}{lcc} 
Candidate gender-prior ties & $\begin{array}{c}\text { Average } \\
\text { partial } \\
\text { effect }\end{array}$ & Std.error \\
\hline Male - No ties & 0.40 & 0.90 \\
Male - Ties & 0.76 & 0.70 \\
Female - No ties & 0.36 & 0.86 \\
Female - Ties & 0.59 & 0.91 \\
\hline Candidate gender - Women on committee - Prior ties & & \\
\hline Female - No women on committee - No prior ties & 0.45 & 0.95 \\
Female - No women on committee - With prior ties & 0.55 & 0.95 \\
Female - Women on committee - No prior ties & 0.56 & 0.96 \\
Female - Women on committee - With prior ties & 0.91 & 0.35 \\
\hline
\end{tabular}

Notes: Predicted probabilities are computed from estimated coefficients from Table 4, column 5 and from a model with three-way interactions that is available upon request.

Table A11 reports the results of a linear probability model, with fixed effects at the call level, for the model with types, intensity of ties and gendered ties as in Table 7 in the main text. 
Table A11-Probability of success - Linear probability model with types, intensity of ties and gendered ties

\begin{tabular}{|c|c|c|c|c|}
\hline Success & 1 & 2 & 3 & 4 \\
\hline Female & $\begin{array}{l}-0.048 \\
(0.049)\end{array}$ & $\begin{array}{l}-0.043 \\
(0.046)\end{array}$ & $\begin{array}{c}-0.026 \\
(0.048)\end{array}$ & $\begin{array}{l}-0.029 \\
(0.046)\end{array}$ \\
\hline Female $\times$ Female (no HR) in Comm. & $\begin{array}{l}0.175^{*} \\
(0.089)\end{array}$ & $\begin{array}{c}0.139 \\
(0.087)\end{array}$ & $\begin{array}{c}0.119 \\
(0.089)\end{array}$ & $\begin{array}{c}0.141 \\
(0.087)\end{array}$ \\
\hline Institution ties & & $\begin{array}{c}0.442^{* * * *} \\
(0.093)\end{array}$ & & \\
\hline Committee ties & & $\begin{array}{c}0.073 \\
(0.070)\end{array}$ & & \\
\hline Intensity of ties & & & $\begin{array}{c}0.251^{* * *} \\
(0.045)\end{array}$ & \\
\hline Male-Male ties & & & & $\begin{array}{l}0.363^{* * *} \\
(0.103)\end{array}$ \\
\hline Female-Male ties & & & & $\begin{array}{c}0.301 \\
(0.195)\end{array}$ \\
\hline Undefined & & & & $\begin{array}{c}0.068 \\
(0.169)\end{array}$ \\
\hline CONTROLS & YES & YES & YES & YES \\
\hline $\mathrm{R}^{2}$ & 0.190 & 0.286 & 0.273 & 0.255 \\
\hline Observations & 608 & 608 & 608 & 608 \\
\hline
\end{tabular}

Notes: The Table reports linear probability model coefficients, with call fixed effects. The dependent variable is a dummy variable for being recruited. Clustered standard errors (at the call level) are reported in parenthesis. In specification (4) the omitted category for the last three variables is having no ties. The symbols *,** and $* * *$ indicate that the coefficients are statistically significant at the $10 \%, 5 \%$ and $1 \%$ levels, respectively. Controls include: H-index std. adj., Age, Age squared, Italian origins, Ph.D., Work experience.

\section{References}

Hirsch JE (2005). An index to quantify an individual's scientific research output. Proceedings of the National Academy of Sciences of the United States of America, 102(46):16569-16572.

Falagas ME, Pitsouni EI, Malietzis GA and Pappas G (2008). Comparison of PubMed, Scopus, Web of Science, and Google scholar: strengths and weaknesses. The FASEB Journal, 22(2):338342.

Meho LI and Rogers Y (2008). Citation counting, citation ranking, and h-index of human-computer interaction researchers: a comparison of Scopus and Web of Science. Journal of the American Society for Information Science and Technology, 59(11):1711-1726. 